Research Journal of Biological Sciences 7 (1): 43-47, 2012

ISSN: $1815-8846$

(C) Medwell Journals, 2012

\title{
Optimization of Polysaccharides Extraction from the Fruiting Bodies of Catathelasma ventricosum Using Response Surface Methodology
}

\author{
${ }^{1,2}$ Ling Zhao, ${ }^{1,}{ }^{2}$ Kaiyu Wang, ${ }^{1}$ Qingjiao Liao, ${ }^{1}$ Rui Zhang and ${ }^{1,2}$ Wei Zhang \\ ${ }^{1}$ College of Veterinary Medicine, \\ ${ }^{2}$ Key Laboratory of Animal Disease and Human Health of Sichuan Province, \\ Sichuan Agricultural University, Ya'an, China
}

\begin{abstract}
In order to maximize the yield of polysaccharides of Catathelasma ventricosum, response surface methodology was applied to optimize the extraction conditions (extraction temperature, ratio of water to raw material and extraction time) of polysaccharides from the fruiting bodies of Catathelasma ventricosum. A box-behnken design was used for experimental design and analysis of the results to obtain the optimal processing parameters. Among the three extraction parameters, the extraction temperature was the most significant factor to affect the yield of polysaccharides from Catathelasma ventricosum. A mathematical model with high determination coefficient was gained and could be employed to optimize polysaccharides extraction and the optimal conditions were extraction temperature $100^{\circ} \mathrm{C}$, ratio of water to raw material $22.78: 1$, extraction time $3.66 \mathrm{~h}$. Under these conditions, the experimental yield of polysaccharide was $6.47 \pm 0.14 \%$ which was close to the predicted value.
\end{abstract}

Key words: Response surface methodology, Catathelasma ventricosum, polysaccharides, optimization, extraction, China

\section{INTRODUCTION}

In recent decades, the biological activities of polysaccharides have attracted more attention in the biochemical and medical fields. A great deal of polysaccharides isolated from mushrooms, fungi, yeast, algae, lichens and plants have been reported to have a broad spectrum of biological activity including antioxidant, anti-inflammatory, anti-cancer, anti-coagulant and immunostimulatory activity (Liao et al., 2011; Chen et al., 2007; Jiao et al., 2009; Yoon et al., 2003; Eo et al., 1999). Mushrooms as one of the most famous resource of traditional Chinese medicines are rich in polysaccharides.

Up to now, many polysaccharides have been isolated from mushrooms such as Ganoderma tsugae, Agaricus blazei, Inonotus obliquus, Tremella fuciformis (Bin, 2010; Liu and Sun, 2011; Rhee et al., 2008) and have been developed into functional foods for sale. Catathelasma ventricosum is one of the most important wild and edible fungus distributed in Heilongjiang, Sichuan, Xizang and Yunnan provinces of China which is a Tricholomataceae fungus belonging to the Basidiomycetes. Although, the fruiting body of Catathelasma ventricosum is not very delicious, it is still welcomed for nutritional value. So far, there is few information published about the water-soluble polysaccharide isolated form this fungus (CVP). In the other study, CVP have been found antioxidant activity in vitro and to have effect on differentiation of preadipocyte. Similar to biological activities of CVP, the extraction of the CVP is still limited. The objective of this study was to optimize extraction condition of the polysaccharides from the fruiting bodies of Catathelasma ventricosum using RSM.

\section{MATERIALS AND METHODS}

The fruiting bodies of Catathelasma ventricosum were obtained from Chuxiong, Yunnan province, China. Phenol was form Bei Jing Solarbio S\&T Co., Ltd. (Beijing, China), sulfuric acid, ethanol and glucose were from the Cheng Du Kelong Chemical Factory (Chengdu, China). All other chemicals were of analytical grade.

Extraction of crude polysaccharides from Catathelasma ventricosum: The fruiting bodies of Catathelasma ventricosum were soaked in 4 volumes of $95 \%$ ethanol for $24 \mathrm{~h}$ to remove lipid. The pretreated powder $(10.0 \mathrm{~g})$ was extracted with the hot distilled water for 3 times in a designed temperature, ratio of water to raw material and

Corresponding Author: Kaiyu Wang,Key Laboratory of Animal Disease and Human Health of Sichuan Province, Sichuan Agricultural University, Ya'an, China 
extraction time and then mixed the three extract liquids together. The supernatant was concentrated in a rotary evaporator at $60^{\circ} \mathrm{C}$ under reduced pressure. The resulting solution was precipitated by the addition of $80 \%(\mathrm{v} / \mathrm{v})$ ethanol and the precipitate was collected by sucking filtration and washed with $100 \%$ ethanol, acetone and finally dried at $55^{\circ} \mathrm{C}$ to obtain crude Polysaccharide of Catathelasma ventricosum (CVP).

Determination of polysaccharides yield: The total sugar content of polysaccharide was measured by the Phenol-sulfuric Acid Method (Dubois et al., 1956), glucose was used as standard and the results were then expressed as glucose equivalents.

Experimental design: Response Surface Methodology (RSM) was used to determine the influence of three independent parameters on the yield of CVP and the optimal conditions of extraction. Three independent parameters namely, the extraction temperature $\left(\mathrm{X}_{1}\right)$, ratio of water to raw material $\left(\mathrm{X}_{2}\right)$ and extraction time $\left(\mathrm{X}_{3}\right)$ at three different levels, each were employed. The parameters were chosen and their levels were based on preliminary experiments carried out in the laboratory.

Box-Behnken Design (BBD) was used in this optimization study. The range of independent variables and their levels were shown in Table 1. Extraction yield (y) was taken as the response for the combination of the independent variables shown in Table 2 . The experiment

Table 1: Independent variables and their levels used in the response surface

\begin{tabular}{llll}
\multicolumn{1}{c}{ design } & & & \\
\hline & Levels & & 1 \\
\hline Factors & -1 & 0 & 100 \\
$\mathrm{X}_{1}$ temperature ${ }^{\circ} \mathrm{C}$ & 80 & 90 & $25: 1$ \\
$\mathrm{X}_{2}$ ratio of water to raw material & $15: 1$ & $20: 1$ & 4 \\
$\mathrm{X}_{3}$ extraction time $\mathrm{h}^{-1}$ & 3 & 3.5 &
\end{tabular}

Table 2: Box-behnken experimental design and results for extraction yield

\begin{tabular}{lcccc}
\hline Run & $\begin{array}{c}\mathrm{X}_{1} / \text { temperature } \\
\left({ }^{\circ} \mathrm{C}\right)\end{array}$ & $\begin{array}{c}\mathrm{X}_{2} / \text { ratio of water } \\
\text { to raw material }\end{array}$ & $\begin{array}{c}\mathrm{X}_{3} / \text { extraction } \\
\text { time (h) }\end{array}$ & Yield (\%) \\
\hline 1 & $0 / 90$ & $0 / 20$ & $0 / 3.5$ & 5.54 \\
2 & $0 / 90$ & $-1 / 15$ & $-1 / 3.0$ & 4.79 \\
3 & $0 / 90$ & $1 / 25$ & $1 / 4.0$ & 5.25 \\
4 & $-1 / 80$ & $1 / 25$ & $0 / 3.5$ & 4.74 \\
5 & $1 / 100$ & $0 / 20$ & $-1 / 3.0$ & 5.57 \\
6 & $0 / 90$ & $0 / 20$ & $0 / 3.5$ & 5.48 \\
7 & $0 / 90$ & $0 / 20$ & $0 / 3.5$ & 5.51 \\
8 & $0 / 90$ & $0 / 20$ & $0 / 3.5$ & 5.61 \\
9 & $1 / 100$ & $-1 / 15$ & $0 / 3.5$ & 5.86 \\
10 & $-1 / 80$ & $-1 / 15$ & $0 / 3.5$ & 4.71 \\
11 & $0 / 90$ & $0 / 20$ & $0 / 3.5$ & 5.59 \\
12 & $0 / 90$ & $-1 / 15$ & $1 / 4.0$ & 5.18 \\
13 & $-1 / 80$ & $0 / 20$ & $1 / 4.0$ & 4.52 \\
14 & $-1 / 80$ & $0 / 20$ & $-1 / 3.0$ & 4.47 \\
15 & $1 / 100$ & $1 / 25$ & $0 / 3.5$ & 6.21 \\
16 & $0 / 90$ & $1 / 25$ & $-1 / 3.0$ & 4.96 \\
17 & $1 / 100$ & $0 / 20$ & $1 / 4.0$ & 6.02 \\
\hline
\end{tabular}

was carried out in a random order. Experiment data were fitted to a Second-order Polynomial Model and regression coefficients obtained which was as follows:

$$
\mathrm{y}=\mathrm{A}_{0}+\sum_{\mathrm{i}=1}^{3} \mathrm{~A}_{\mathrm{i}} \mathrm{X}_{\mathrm{i}}+\sum_{\mathrm{i}=1}^{3} \mathrm{~A}_{\mathrm{ii}} \mathrm{X}_{\mathrm{i}}^{2}+\sum_{\mathrm{i}=1}^{2} \sum_{\mathrm{j}=\mathrm{i}+1}^{3} \mathrm{~A}_{\mathrm{ij}} \mathrm{X}_{\mathrm{ij}}
$$

Where:

$\mathrm{y}=$ The dependent variable

$\mathrm{A}_{0} \quad=$ An intercept

$\mathrm{A}_{\mathrm{i}}, \mathrm{A}_{\mathrm{ii}}$ and $\mathrm{A}_{\mathrm{ij}}=$ The coefficients of the linear, quadratic and interactive terms, respectively by the model

$\mathrm{X}_{\mathrm{i}}, \mathrm{X}_{\mathrm{ij}}=$ Levels of the independent variables

The model evaluated the effect of each independent variable to a response. Three additional confirmation experiments were conducted to verify the validity of the statistical experimental strategies.

Statistical analysis: RSM was performed using the Design Expert Software (Version 8.0.6, Stat-Ease. Inc., Minneapolis, MN). The significances of the regression coefficient were checked by the F-test and p-value. The corresponding variables would be more significant if the absolute $\mathrm{F}$-value becomes greater and the p-value becomes smaller.

\section{RESULTS AND DISCUSSION}

Fitting the model: The experimental data for extraction yield of the CVP under different treatment conditions are shown in Table 3 . The statistical analysis indicated that the proposed regression model for yield was adequate, possessing to significant lack of fit and with satisfactory values of the $\mathrm{R}^{2}$ for all the responses. The closer the value of $\mathrm{R}^{2}$ to the unity, the better the empirical model fits the actual data.

The determination coefficient $\left(\mathrm{R}^{2}=0\right.$. 9957) was showed by ANOVA of the Quadratic Regression Model indicating that only $0.43 \%$ of the total variations were not explained by the model. The coefficient of the variation $(\mathrm{CV}=0.95 \%)$ indicated a good deal of reliability of the experimental values. The results of the analysis of

Table 3: Analysis of variance for the fitted quadratic polynomial model of extraction of polysaccharides

\begin{tabular}{lccccc}
\hline Parameters & $\begin{array}{c}\text { Sum of } \\
\text { squares }\end{array}$ & $\begin{array}{c}\text { Degrees of } \\
\text { freedom }\end{array}$ & Mean square & F-value & p-value \\
\hline Model & 4.400 & 9 & 0.4880 & 192.105 & $<0.0001$ \\
Residual & 0.018 & 7 & 0.0025 & - & - \\
Lack of fit & 0.006 & 3 & 0.0020 & 0.691 & 0.6035 \\
Pure error & 0.012 & 4 & 0.0029 & - & - \\
Cor total & 4.413 & 16 & - & - & - \\
\hline
\end{tabular}


variance, goodness-of-fit and the adequacy of the models are summarized. The percentage yield ranged from 4.47-6.21\%. The maximum yield of polysaccharide $(6.21 \%)$ was recorded under the experimental conditions of extraction temperature $100^{\circ} \mathrm{C}$, ratio of water to raw material 25:1 and extraction time $3.5 \mathrm{~h}$.

By applying multiple regression analysis on the experimental data, predicted response $y$ for the yield of polysaccharides could be expressed by the following second-order polynomial equation in terms of actual values:

$$
\begin{aligned}
\mathrm{y}= & -15.742+0.0188 \mathrm{X}_{1}+0.1213 \mathrm{X}_{2}+8.9215 \mathrm{X}_{3}+ \\
& 0.0016 \mathrm{X}_{1} \mathrm{X}_{2}+0.0205 \mathrm{X}_{1} \mathrm{X}_{3}-0.01 \mathrm{X}_{2} \mathrm{X}_{3}- \\
& 0.0003175 \mathrm{X}_{1}^{2}-0.00537 \mathrm{X}_{2}^{2}-1.467 \mathrm{X}_{3}^{2}
\end{aligned}
$$

Where:

$\mathrm{y}=$ The polysaccharides yield

$\mathrm{X}_{1}-\mathrm{X}_{3}=$ The actual values for extraction temperature, ratio of water to raw material and extraction time, respectively

The analysis of variance for these modes was given in Table 4. In Table 4 , the linear coefficients $\left(\mathrm{X}_{1}-\mathrm{X}_{3}\right)$, the quadratic term coefficients $\left(\mathrm{X}_{2}^{2}, \mathrm{X}^{2}\right)$ and the interaction coefficients $\left(\mathrm{X}_{1} \mathrm{X}_{2}, \mathrm{X}_{1} \mathrm{X}_{3}\right)$ were significant $(\mathrm{p}<0.01)$.

And a quadratic term coefficient $\left(\mathrm{X}_{1}^{2}\right)$ and a interaction coefficient $\left(\mathrm{X}_{2} \mathrm{X}_{3}\right)$ were not significant $(\mathrm{p}>0.05)$. The full model filled (Eq. 2) was made three dimensional and contour plots to predict the relationships between the independent variables and the dependent variables.

Optimization of the process: The graphical representations of the regression (Eq. 2) called the response surfaces and the contour plots were obtained using Design-Expert 8.0.6. As shown in Fig. 1-3,

Table 4: Regression coefficients estimate and their significance test for the Quadratic Polynomial Model

\begin{tabular}{lcccrr}
\hline Parameters & $\begin{array}{c}\text { Sum of } \\
\text { squares }\end{array}$ & $\begin{array}{c}\text { Degrees of } \\
\text { freedom }\end{array}$ & $\begin{array}{l}\text { Mean } \\
\text { square }\end{array}$ & F-values & p-values \\
\hline $\mathrm{X}_{1}$ & 3.4200 & 1 & 3.4200 & 1344.970 & $<0.0001$ \\
$\mathrm{X}_{2}$ & 0.0480 & 1 & 0.0480 & 18.900 & 0.0034 \\
$\mathrm{X}_{3}$ & 0.1770 & 1 & 0.1770 & 69.631 & $<0.0001$ \\
$\mathrm{X}_{1} \mathrm{X}_{2}$ & 0.0260 & 1 & 0.0260 & 10.070 & 0.0156 \\
$\mathrm{X}_{1} \mathrm{X}_{3}$ & 0.0420 & 1 & 0.0420 & 16.531 & 0.0048 \\
$\mathrm{X}_{2} \mathrm{X}_{3}$ & 0.0025 & 1 & 0.0025 & 0.983 & 0.3544 \\
$\mathrm{X}_{1} \mathrm{X}_{1}$ & 0.0042 & 1 & 0.0042 & 1.670 & 0.2373 \\
$\mathrm{X}_{2} \mathrm{X}_{2}$ & 0.0760 & 1 & 0.0760 & 29.851 & 0.0009 \\
$\mathrm{X}_{3} \mathrm{X}_{3}$ & 0.5660 & 1 & 0.5660 & 222.780 & $<0.0001$ \\
\hline
\end{tabular}

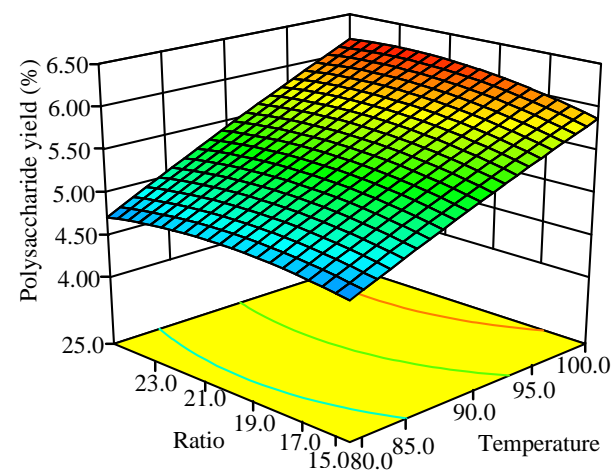

Design-Expert Software

Factor coding: Actual

6.21

4.47

$\mathrm{X}_{1}=\mathrm{A}:$ Temperature

$\mathrm{X}_{2}=\mathrm{B}$ : Ratio of water to raw material

Actual factor

C: Extraction time $=3.50$

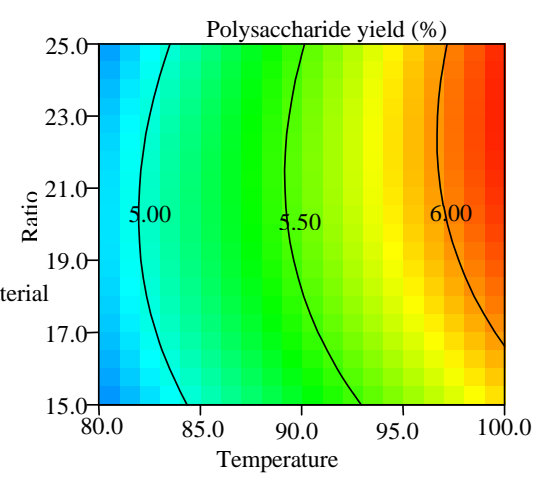

Fig. 1: Response surface plot and contour of ratio of water to raw material and temperature and their mutual interactions on the yield of polysaccharides
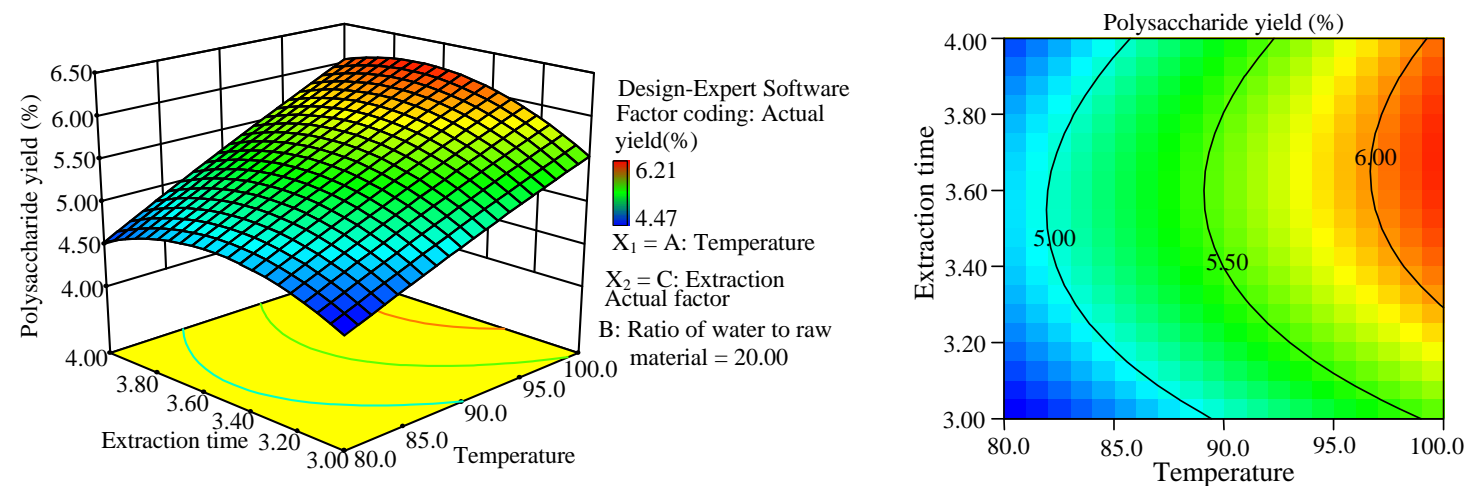

Fig. 2: Response surface plot and contour of extraction time and temperature and their mutual interactions on the yield of polysaccharides 

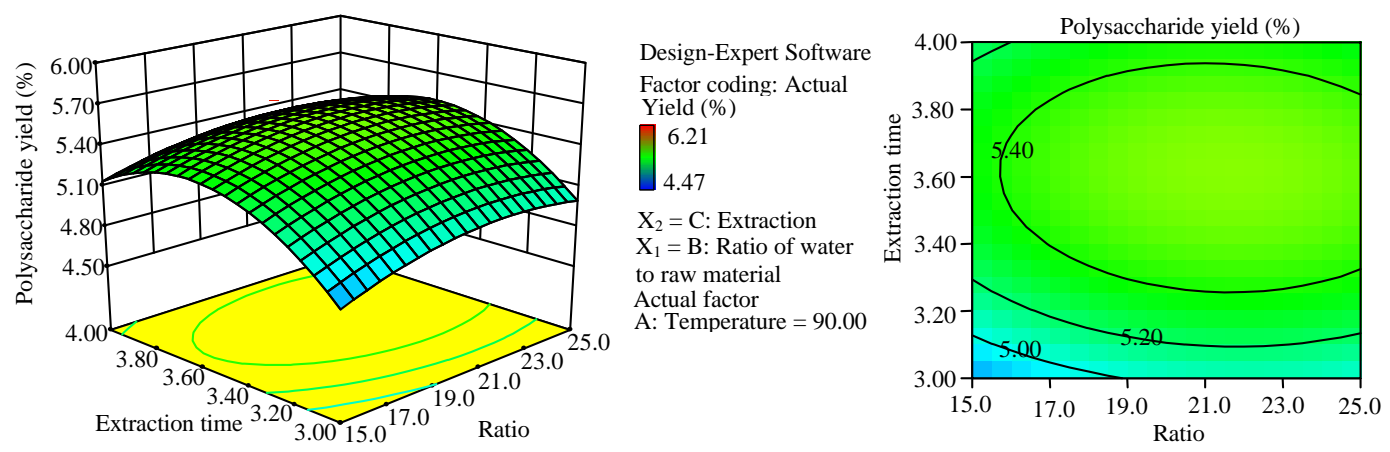

Fig. 3: Response surface plot and contour of extraction time and ratio of water to raw material and their mutual interactions on the yield of polysaccharides

3-D response surface plots and 2-D contour plots were useful to see interaction effects of the factors on the responses. They provide a method to visualize the relationship between responses and experimental levels of each variable and the type of interactions between two test variables. Figure 1 indicates the effects of ratio of water to raw material and extraction temperature on the extraction yield of CVP at extraction time of $3.5 \mathrm{~h}$.

It can be seen that the temperature and ratio of water to raw material had positive impact on the yield of CVP. The yield of polysaccharides increased rapidly with increasing of extraction temperature from $80-100^{\circ} \mathrm{C}$. And the yield of CVP increased slightly with increasing of ratio of water to raw material from 15:1-22.78:1 but beyond $22.78: 1$, the extraction yield of polysaccharides decreased slightly.

Figure 2 shows the effects of extraction time and extraction temperature on the extraction yield of CVP at ratio of water to raw material of 20:1. The extraction yield of polysaccharides increased rapidly with increasing of extraction temperature from $80-100^{\circ} \mathrm{C}$ and increased with increasing of extraction time from 3-3.66 $\mathrm{h}$ then descended with increasing of extraction time.

Figure 3 shows the effects of extraction time and ratio of water to raw material on the extraction yield of CVP at extraction temperature of $90^{\circ} \mathrm{C}$. The extraction yield of polysaccharides increased gradually with increasing of ratio of water to raw material from 15:1-22.78:1 then decreased slightly from 22.78:1-25:1. The yield of polysaccharides rapidly increased with increasing of extraction time from 3-3.66 $\mathrm{h}$ then descended with increasing of extraction time.

According to Fig. 1-3, optimal extraction conditions of CVP were extraction temperature $100^{\circ} \mathrm{C}$, ratio of water to raw material $22.78: 1$, extraction time $3.66 \mathrm{~h}$, respectively. Among the three extraction parameters studied, the extraction temperature was the major factor affecting the extraction yield of CVP followed by extraction time and ratio of water to raw material according to the regression
Table 5: Fit statistics for y

\begin{tabular}{lcc}
\hline Stat. methods & Master model & Predictive model \\
\hline Mean & 5.295 & 5.295 \\
$\mathrm{R}^{2}$ & $99.60 \%$ & $99.60 \%$ \\
Adj. $\mathrm{R}^{2}$ & $99.08 \%$ & $99.08 \%$ \\
RMSE & 0.05 & 0.05 \\
CV (\%) & 0.95 & 0.95 \\
\hline
\end{tabular}

Table 6: Predicted and experimental values of the responses at optimum and modified conditions

\begin{tabular}{lcccl}
\hline & \multicolumn{3}{c}{ Ratio of water } & \multicolumn{2}{c}{$\begin{array}{c}\text { Extraction } \\
\text { Conditions }\end{array}$} & Temperature & to raw material & time (h) & Yield (\%) \\
\hline Optimum conditions & 100 & 22.78 & 3.66 & 6.25 \\
Modified conditions & 100 & 22.80 & 3.70 & $6.47 \pm 0.14$ \\
\hline
\end{tabular}

coefficients significance of the quadratic polynomial model (Table 4) and gradient of slope in the 3-D response surface plot (Fig. 1-3). The result was in agreement with previous investigation (Han et al., 2011).

The occurrence that the increase of the yield of polysaccharides with increase of extraction temperature, might due to the induced cell wall distuption and solubilization of cell wall materials at higher temperature and enhance mass transfer rates (Ye and Jiang, 2011; Guo et al., 2010). Under some temperature, the yield of polysaccharide increased slightly with increasing of extraction time and ratio of water to raw material then dropped. This situation might due to the polysaccharide hydrolysis under long extraction time and more solvent (Table 5 and 6).

Confirmative tests: In order to validate the adequacy of the model equations (Eq. 2), a verification experiment was carried out using the recommended optimum conditions. The maximum predicted yield and experimental yield of CVP were shown in Table 4. Under the modified conditions, the experimental yield of polysaccharide was $6.47 \pm 0.14 \%(n=3)$ which was close to the predicted value. The good correlation between these results confirmed that the model was adequate for reflecting the expected optimization. 


\section{CONCLUSION}

In this study, RSM was successfully used to determine the extraction conditions for CVP. The optimal extraction conditions for the polysaccharides were as follows: extraction temperature $100^{\circ} \mathrm{C}$, extraction time $3.66 \mathrm{~h}$, ratio of water to raw material $22.78: 1$.

\section{ACKNOWLEDGEMENTS}

This research was supported by the Department of Science and Technology of Sichuan province of China (No. 09ZA083) and the Program for Changjiang Scholars and Innovative Research Team in University (No. IRT0848).

\section{REFERENCES}

Bin, C., 2010. Optimization of extraction of Tremella fuciformis polysaccharides and its antioxidant and antitumour activities in vitro. Carbohydr. Polym., 81: $420-424$.

Chen, J., T. Hu and R. Zheng, 2007. Antioxidant activities of Sophora subprosrate polysaccharide in immunosuppressed mice. Int. Immunopharmacol., 7: $547-553$.

DuBois, M., K.A. Gilles, J.K. Hamilton, P.A. Rebers and F. Smith, 1956. Colorimetric method for determination of sugars and related substances. Anal. Chem., 28: $350-356$.

Eo, S.K., Y.S. Kim, C.K. Lee and S.S. Han, 1999. Antiviral activities of various water and methanol soluble substances isolated from Ganoderma lucidum. J. Ethnopharmacol., 68: 129-136.
Guo, X., X. Zou and M. Sun, 2010. Optimization of extraction process by response surface methodology and preliminary characterization of polysaccharides from Phellinus igniarius. Carbohydr. Polym., 80: 344-349.

Han, J., X. Jiang and L. Zhang, 2011. Optimisation of extraction conditions for polysaccharides from the roots of Isatis tinctoria L. by response surface methodology and their in vitro free radicals scavenging activities and effects on IL-4 and IFN- $\gamma$ mRNA expression in chicken lymphocytes. Carbohydr. Polym., 86: 1320-1326.

Jiao, L., X. Li, T. Li, P. Jiang, L. Zhang, M. Wu and L. Zhang, 2009. Characterization and anti-tumor activity of alkali-extracted polysaccharide from Enteromorpha intestinalis. Int. Immunopharmacol., 9: 324-329.

Liao, C.H., S.J. Guo and J.Y. Lin, 2011. Characterisation of the chemical composition and in vitro antiinflammation assessment of a novel lotus (Nelumbo nucifera Gaertn) plumule polysaccharide. Food Chem., 125: 930-935.

Liu, J. and Y. Sun, 2011. Structural analysis of an alkaliextractable and water-soluble polysaccharide (ABPAW1) from the fruiting bodies of Agaricus blazei Murill. Carbohydr. Polym., 86: 429-432.

Rhee, S.J., S.Y. Cho, K.M. Kim, D.S. Cha and H.J. Park, 2008. A comparative study of analytical methods for alkali-soluble $\beta$-glucan in medicinal mushroom, Chaga (Inonotus obliquus). LWT-Food Sci. Technol., 41: 545-549.

Ye, C.L. and C.J. Jiang, 2011. Optimization of extraction process of crude polysaccharides from Plantago Asiatica L. by response surface methodology. Carbohydr. Polym., 84: 495-502.

Yoon, S.J., M.A. Yu, Y.R. Pyun, J.K. Hwang, D.C. Chu, L.R. Juneja and P.A.S. Mourao, 2003. The nontoxic mushroom Auricularia auricula contains a polysaccharide with anticoagulant activity mediated by antithrombin. Thrombosis Res., 112: 151-158. 